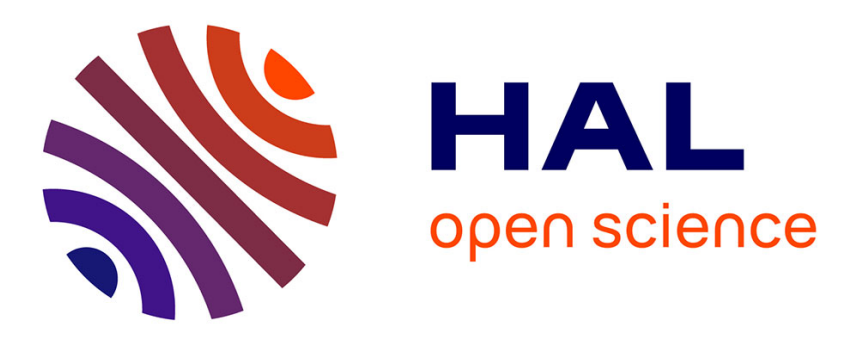

\title{
Self-Assembled Monolayers of Redox-Active 4d-4f Heterobimetallic Complexes
}

\author{
Andrea Mulas, Galina V Dubacheva, Hassan Al Sabea, Fabien Miomandre, \\ Jean-Frédéric Audibert, Lucie Norel, Stéphane Rigaut, Corinne Lagrost
}

\section{- To cite this version:}

Andrea Mulas, Galina V Dubacheva, Hassan Al Sabea, Fabien Miomandre, Jean-Frédéric Audibert, et al.. Self-Assembled Monolayers of Redox-Active 4d-4f Heterobimetallic Complexes. Langmuir, 2019, 35 (42), pp.13711-13717. 10.1021/acs.langmuir.9b02083 . hal-02364872

HAL Id: hal-02364872

https://hal-univ-rennes1.archives-ouvertes.fr/hal-02364872

Submitted on 21 Feb 2020

HAL is a multi-disciplinary open access archive for the deposit and dissemination of scientific research documents, whether they are published or not. The documents may come from teaching and research institutions in France or abroad, or from public or private research centers.
L'archive ouverte pluridisciplinaire HAL, est destinée au dépôt et à la diffusion de documents scientifiques de niveau recherche, publiés ou non, émanant des établissements d'enseignement et de recherche français ou étrangers, des laboratoires publics ou privés. 


\title{
Self-assembled monolayers of redox active 4d-4f heterobimetallic complexes
}

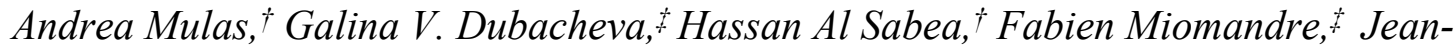 \\ Frédéric Audibert,,+ Lucie Norel, ${ }^{\dagger} * *$ Stéphane Rigaut ${ }^{\dagger, *}$ and Corinne Lagrost ${ }^{\dagger, *}$
}

† Univ Rennes, CNRS, ISCR (Institut des Sciences Chimiques de Rennes) - UMR 6226, F35000 Rennes, France

† UMR CNRS 8531-PPSM, ENS Cachan, Université Paris-Saclay, 61 Avenue Président Wilson, 94235 Cachan, France

\begin{abstract}
In this work, we report the preparation of functional interfaces incorporating heterobimetallic systems consisting in the association of an electroactive carbon-rich ruthenium organometallic unit and a luminescent lanthanide ion $\left(\mathrm{Ln}=\mathrm{Eu}^{3+}\right.$ and $\left.\mathrm{Yb}^{3+}\right)$. The organometallic systems are functionalized with a terminal hexylthiol group for subsequent gold surface modification. Formation of self-assembled monolayers (SAMs) with these complex molecular architectures are thoroughly demonstrated by employing a combination of different techniques, including IRRAS spectroscopy, ellipsometry, contact angle and cyclic voltammetry measurements. The immobilized heterobimetallic systems show fast electrontransfer kinetics, hence are capable of fast electrochemical response. In addition, the characteristic electrochemical signals of the SAMs were found to be sensitive to the presence of lanthanide centers at the bipyridyl terminal units. A positive shift of the potential of the redox signal is readily observed for lanthanide complexes compared to the bare organometallic ligand. This effect is equally observed for pre-formed complexes and for on-surface complexation. Thus, an efficient ligating recruitment of europium and ytterbium cations at gold-modified electrodes is demonstrated, allowing for an easy electrochemical detection of
\end{abstract}


the lanthanide ions along with an alternative preparative method of SAMs incorporating lanthanide cations compared to the immobilization of preformed complex.

\section{INTRODUCTION}

Immobilization through self-assembled monolayers (SAMs) at surfaces of specifically designed molecular systems, notably those incorporating redox-active units provides a robust and simple way to obtain complex and functional architectures from smallest building blocks. ${ }^{1,2}$ Thus, many applications of such systems have been developed including inter alia chemical or biological sensing, data storage, molecular electronics or heterogeneous catalysis. Based on a spontaneous process, this offers the possibility of forming practical devices able to operate with much more ordered and available species than in solution, a key point for further device incorporation. Integrating luminescent species into such systems is particularly attracting in order to investigate or to monitor the properties and function of the assemblies with fast response time and high sensitivity. In this context, lanthanide-based complexes are particularly interesting because of their photophysical characteristics, notably sharp, well-defined, characteristic fingerprint emission bands, as well as long lifetimes. ${ }^{3-5}$ Despite the expected potential of lanthanide complexes luminescence for a number of applications, still very few architectures incorporating lanthanides ions at solid interfaces have been reported so far. Lanthanides complexes have been grafted onto Si or silica surfaces. ${ }^{6-9}$ Langmuir-Blodgett layers or molecular printboards using $\beta$-cyclodextrins have been also employed to immobilize lanthanides complexes. ${ }^{10,11}$ Immobilization procedure involving anchoring thiols groups have been described onto gold planar surfaces, ${ }^{12-15}$ but also onto gold nanoparticles. ${ }^{16-18}$

Most of these works report on europium complexes, while ytterbium centers are rarely implemented. Even rarer is the combination of redox-active unit with a lanthanide complex. 
Indeed, only one work reports on the combination of electroactive moiety (ferrocene) with a europium complex in order to obtain an electrofluorochromic molecular film. ${ }^{14}$ Herein, we report the preparation of functional redox active interfaces incorporating analogous heterobimetallic ruthenium-lanthanide architectures including europium and for the first time ytterbium ions. Indeed, we have previously described molecular compounds based on the association of organometallic ruthenium acetylide moieties with europium, neodymium and ytterbium centers. ${ }^{19,20}$ The carbon-rich ruthenium $\sigma$-arylacetylide is a very interesting building block because it exhibits low oxidation potential with stable redox state and promotes strong electronic coupling between the metal and the organic ligands. ${ }^{20-23}$ This organometallic moiety turned out to be an attractive platform in order to achieve redox event ${ }^{19-20,24}$ and to introduce grafting groups for building functional redox active surfaces. ${ }^{25-27}$ Before forming the SAMs, the organometallic complexes were thoroughly characterized in solution and the redox and optical properties (including NIR emissions) of the heterobimetallic compounds were found to be retained after the introduction of the anchoring hexylthiol chain. The resulting SAMs were analyzed with different techniques including IRRAS spectroscopy, ellipsometry, contact angle and cyclic voltammetry experiments, showing fast electron-transfer kinetics. Interestingly, the characteristic electrochemical signals of the SAMs, were found to be sensitive to the presence of lanthanide centers at the bipyridyl terminal units. This allows to efficiently demonstrate a ligating recruitment of europium and ytterbium cations at gold-modified electrodes and therefore achieving an effective and original $\mathrm{Eu}^{3+}$ and $\mathrm{Yb}^{3+}$ electrochemical detection tool.

\section{EXPERIMENTAL SECTION}

Self-assembled monolayers preparation. SAMs were prepared employing Au disk electrodes from $\mathrm{CH}$ instruments, Inc. (diameter $1.6 \mathrm{~mm}$ ) or Au plates of approximately $1 \mathrm{~cm}^{2}$ area (Au 
deposited onto silicon wafer with a layer thickness of $1000 \AA$ purchased from Sigma Aldrich). Prior to functionalization, the Au electrode surface was thoroughly polished using alumina suspension $(0.3 \mu \mathrm{m})$, then extensively rinsed with ultrapure $\mathrm{H}_{2} \mathrm{O}(18.2 \mathrm{M} \Omega \cdot \mathrm{cm})$. Following the polishing treatment, they were cleaned by immersion in Piranha solution, rinsed with ultrapure $\mathrm{H}_{2} \mathrm{O}$ and high purity EtOH and dried under a stream of argon. The Au plates were cleaned by immersion in a Piranha solution, rinsing with semiconductor grade $\mathrm{MOS}_{2} \mathrm{SO}_{4}(96 \%)$, then rinsed thoroughly with ultrapure $\mathrm{H}_{2} \mathrm{O}$ and high purity EtOH, and finally dried under a stream of argon. . Semi-transparent Au surfaces were prepared by spattering Au onto ITO substrates (100 nm ITO on glass; resistance of $58.5 \Omega$; Saint Gobain). Before Au deposition, ITO surfaces were cleaned by immersing in isopropanol during $20 \mathrm{~min}$, rinsed with isopropanol and dried. Au deposition was done using EMITECH K650 sputter coater. The following conditions were applied: Ar atmosphere (0.1 mbar) at $60 \mathrm{~mA}$ during $4 \mathrm{~min}$. AFM characterization (Thermo Microscope, Veeco; PPD-NCHR-50 Nanosensors) confirmed homogeneous grain-like Au coatings with thickness of $11 \pm 2 \mathrm{~nm}$ and RMS roughness of $2.0 \pm 0.3 \mathrm{~nm}$. Caution! Piranha solution is a very strong oxidant and is extremely dangerous to work with; it should be handled very carefully. The surface functionalization was achieved under inert atmosphere in a glovebox by soaking the gold substrates in a freshly prepared $\mathrm{CH}_{2} \mathrm{Cl}_{2}$ solution of $\mathbf{1}, \mathbf{1} \mathbf{Y b}$ or 1Eu for 16 to 48 hours. Solutions of the complexes $(1 \mathrm{mg} / \mathrm{mL})$ were prepared in the glovebox by adding $\mathrm{NH}_{4} \mathrm{OH}\left(28 \%\right.$ in $\left.\mathrm{H}_{2} \mathrm{O}\right)(1 \mu \mathrm{L} / \mathrm{mL})$ and stirring the solutions over 30 minutes to yield the deprotected thiols before immersing the gold substrates. After formation of the SAMs, the gold supports were gently and thoroughly rinsed with freshly distilled $\mathrm{CH}_{2} \mathrm{Cl}_{2}$, and dried under a stream of argon.

SAMs analyses. SAMs were analyzed by contact angle measurements, ellipsometry, IRRAS spectroscopy and cyclic voltammetry. 
Contact angle measurements were carried out with on a easy drop goniometer (Krüss) equipped with a camera using sessile drop method ( $2 \mu \mathrm{L}$ of ultrapure water drops). Contact angles were calculated over an average of 5 measurements. They were determined using a tangent or circle fitting model.

Reflection-absorption infrared spectra were recorded using a Bruker Vertex 70 Spectrometer. In these experiments the infrared beam was incident at an $80^{\circ}$ angle from the normal to the surface. A total of 1024 scans were collected at $1.0 \mathrm{~cm}^{-1}$ resolution.

The thicknesses of the layers were measured using a spectroscopic ellipsometer $\square$ SE (J.A. Woollam, Co.). The polarization angles $\Psi$ and $\Delta$ were recorded in the $380-900 \mathrm{~nm}$ wavelength range at different incident angles, $65^{\circ}, 70^{\circ}, 75^{\circ}$. The optical constant were fitted by assuming $\mathrm{n}=1.50$ (refraction index) and $\mathrm{k}=0$ (extinction coefficient). Thickness value was obtained through an averaging of 5 measurements.

Cyclic voltammetry experiments were performed in dry (freshly distilled) and thoroughly degassed $\mathrm{CH}_{2} \mathrm{Cl}_{2}$ containing $0.2 \mathrm{M} \mathrm{Bu}_{4} \mathrm{NPF}_{6}$ under an Ar blanket. A Pt wire serves as counter electrode and a SCE reference electrode fitted with a bridge containing $0.2 \mathrm{M} \mathrm{Bu}_{4} \mathrm{NPF}_{6}$ in $\mathrm{CH}_{2} \mathrm{Cl}_{2}$. The voltammograms were recorded using an Eco Chemie Autolab PGSTAT 302N equipped with FRA2.V10 and SCAN 250 modules for iR compensation and high speed measurements. Surface concentration $(\Gamma)$ was determined from Faraday's law, $\Gamma=Q / n F A \rho$ where $Q$ is the charge obtained from the integration of the area under the voltammetric peaks, $n$ is the number of electrons involved in the electron-transfer process (here $n=1$ ), $F$ is the Faraday constant and $A$ is the geometric area of the electrodes, $\rho$ is the roughness factor of the polycrystalline gold disk electrode. $\rho$ was estimated to 1.8 , in full agreement with previously reported values. ${ }^{28-31}$ Estimation of the electronic rate constant for the immobilized complexes was achieved by considering a Butler-Volmer law for the electron transfer and transfer 
coefficient equal to 0.5 . Numerical simulations were KISSA-1D software package (KISSA software for simulation of electrochemical reaction mechanisms of any complexity, http://ww.kissagroup.com/) and using the default parameters for adsorbed species. ${ }^{32}$ Fluorescence measurements were done using an inverted microscope (Ti Eclipse Nikon) with x40 NA0.6 objective in a wide field epi-illumination. The samples were excited by Hg lamp (Intensilight Nikon) coupled to a band pass excitation filter BP $447+/-30 \mathrm{~nm}$ and mCherry dichroic. Emitted light was collected through a long pass emission filter LP $600 \mathrm{~nm}$. Emission spectra were recorded in the range from 700 to $1100 \mathrm{~nm}$ with a Maya2000 Pro spectrometer (OceanOptics) equipped with a $\mathrm{HCl}$ grating. The corresponding mode field diameter of the detection in the sample plane is about $60 \mu \mathrm{m}$.

\section{RESULTS AND DISCUSSION}

Synthesis of the Ruthenium complexes. The complexes were prepared as sketched on scheme 1. First, following a classical procedure, ${ }^{19}$ combinations of $\mathrm{H}-\mathrm{C} \equiv \mathrm{C}-$ bipy $^{33}$ with the vinylidene precursor trans- $\left[\mathrm{Cl}(\right.$ dppe $\left.) \mathrm{Ru}=\mathrm{C}=\mathrm{C}(\mathrm{H})-\mathrm{C}_{6} \mathrm{H}_{4}-\mathrm{O}-\left(\mathrm{CH}_{2}\right)_{6}-\mathrm{SAc}\right][\mathrm{TfO}],{ }^{34}$ in the presence of a non-coordinating salt $\left(\mathrm{NaPF}_{6}\right)$ and a base $\left(\mathrm{Et}_{3} \mathrm{~N}\right)$, led in good yield $(82 \%)$ to the adducts $\mathbf{1}$ bearing one bypiridine function, which was characterized by means of ${ }^{31} \mathrm{P},{ }^{1} \mathrm{H},{ }^{13} \mathrm{C} \mathrm{NMR}$, IR spectroscopies and mass spectrometry. As characteristic features, we observed the expected $\nu_{(\mathrm{C} \equiv \mathrm{C})}$ vibration stretch for the acetylide complexes at $2058 \mathrm{~cm}^{-1}$ in the FTIR spectra, a single resonance peak in the ${ }^{31} \mathrm{P}$ NMR spectrum for a trans arrangement on the ruthenium atom in the typical region for bis( $\sigma$-arylacetylide $)$ at $\delta=53.7 \mathrm{ppm}$, and the characteristic resonances of the $\mathrm{H}_{6}$ protons of non-coordinated bipyridine units in the ${ }^{1} \mathrm{H}$ NMR spectrum around $\delta=8 \mathrm{ppm}$. Further combination of equimolar quantities of $\left[\mathrm{Ln}(\mathrm{TTA})_{3} \cdot 2 \mathrm{H}_{2} \mathrm{O}\right](\mathrm{Ln}=\mathrm{Eu}, \mathrm{Yb})$ and of bipyridyl complex $\mathbf{1}$ in dichloromethane led to the precipitation of the desired heterobimetallic 
complexes $1 \mathbf{E u}$ and $\mathbf{1 Y b}$. The FTIR measurements show for those two acetylide adducts a shift of the $\square$ (C=C) vibration stretch to lower energy, i.e. to 2031 and $2042 \mathrm{~cm}^{-1}$, respectively, and the carbonyl vibration stretches for the TTA ligands at ca. 1600 and $1630 \mathrm{~cm}^{-1}$. The structures of these new compounds were confirmed with the help of ${ }^{31} \mathrm{P}$ NMR and ${ }^{1} \mathrm{H}$ NMR spectroscopies (Figures S1-S6). For example, in a $d^{2}$-dichloromethane solution, the ${ }^{1} \mathrm{H}$ NMR spectra of the paramagnetic complex $\mathbf{1 E u}$ and $\mathbf{1 Y b}$ show only one set of signals at room temperature in agreement with an overall threefold solution structure of the TTA ligands around the metal center. ${ }^{19}$ Paramagnetic shifts are observed due to the through space interactions between the observed nuclei and the $4 \mathrm{f}$ unpaired electrons (pseudo-contact shifts) with, as an example, a paramagnetic shifts for the $\mathrm{H}_{6 / 6}$, bipyridine protons up to $22.54 \mathrm{ppm}$ for $\mathbf{1 Y \mathbf { b }}$.

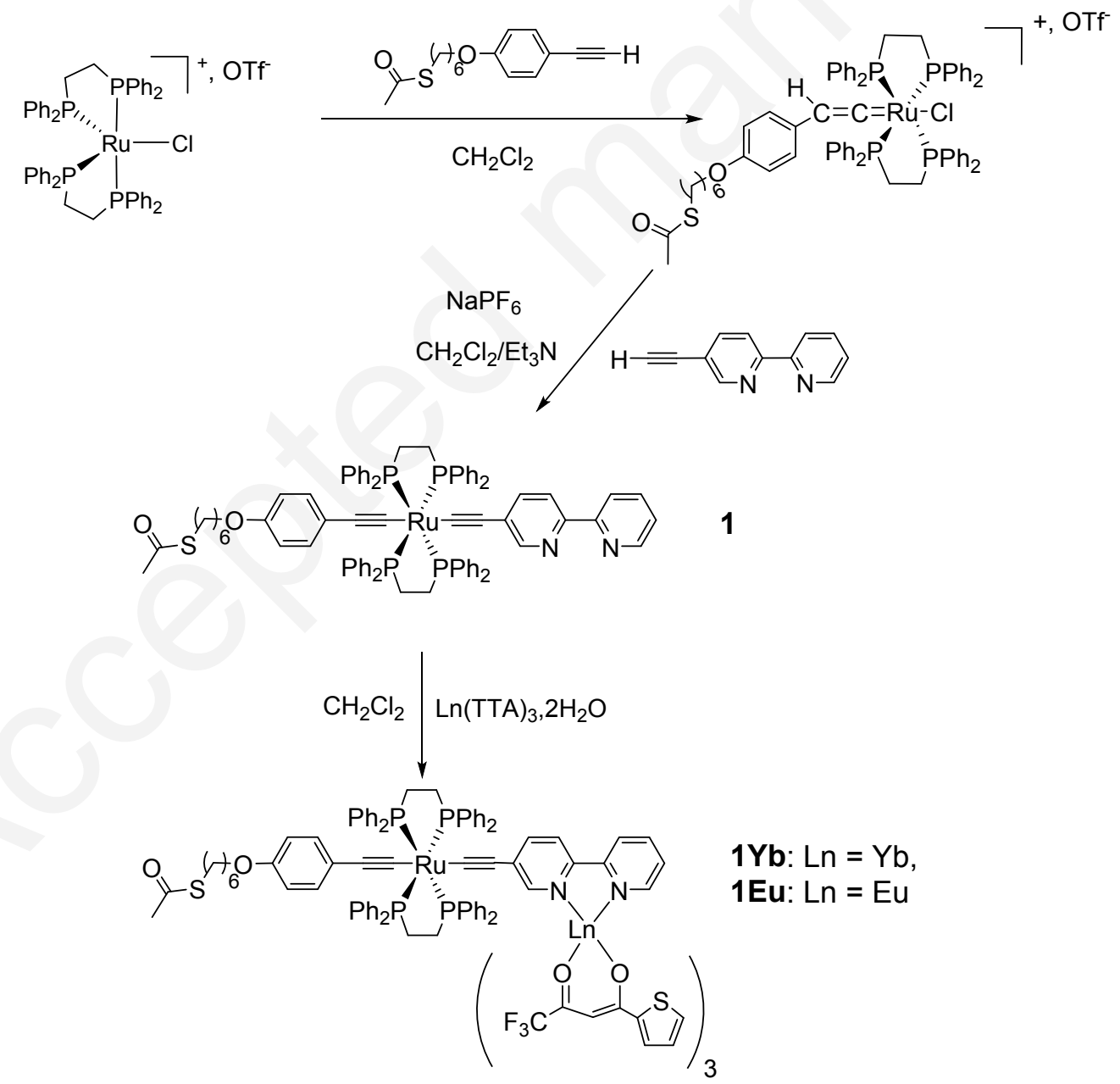

Scheme 1. Synthesis of complexes 1 and $\mathbf{1 L n}(\mathrm{Ln}=\mathrm{Yb}, \mathrm{Eu})$. 
Optical properties. The optical properties of the three complexes were studied in $\mathrm{CH}_{2} \mathrm{Cl}_{2}$ solutions (Figure 1). As expected, the ruthenium(II) complex 1 shows one main absorption bands above $300 \mathrm{~nm}$ at $\lambda_{\max }=401 \mathrm{~nm}\left(\varepsilon=23500 \mathrm{~mol}^{-1}\right.$.L $)$ due to a charge transfer from $\operatorname{Ru}(\mathrm{d} \pi) /$ alkynyl based orbitals to a $\pi^{*}$ orbital based on the bipyridine unit. ${ }^{19}$ A marked bathochromic shift of this transition to $\lambda_{\max } \approx 464 \mathrm{~nm}\left(\varepsilon 23000 \mathrm{~mol}^{-1} . \mathrm{L}, \Delta \lambda=59 \mathrm{~nm}\right)$ was observed in in 1Eu and $\mathbf{1 Y b}$ upon complexation of the $\mathrm{Eu}(\mathrm{III})$ and $\mathrm{Yb}$ (III) ions along with a new absorption at $\lambda_{\max } \approx 334 \mathrm{~nm}$ assigned to the TTA ligand absorption overlapping with transitions of $\pi-\pi^{*}$ character centered on the bipyridyl moieties. Note that, at concentrations of c.a. $10^{-5} \mathrm{M}$, the absorption spectra of $\mathbf{1 Y b}$ and $\mathbf{1 E u}$ do not show the presence of the band at ca. $400 \mathrm{~nm}$ characteristic of uncomplexed ligand $\mathbf{1}$.

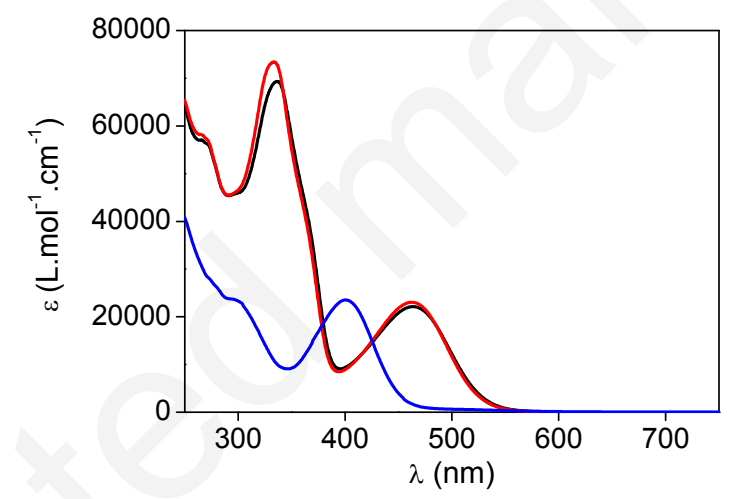

Figure 1. Absorption spectra of $\mathbf{1}$ (blue line) $\mathbf{1 E u}$ (black line) and $\mathbf{1 Y b}$ (red line) in $\mathrm{CH}_{2} \mathrm{Cl}_{2}$ $\left([\mathrm{C}] \approx 10^{-5} \mathrm{~mol} \cdot \mathrm{L}^{-1}\right)$.

The emission properties were first studied on the $\mathrm{Yb}$ complex. Excitation in the aforementioned lower energy transition $\left(\lambda_{\mathrm{ex}}=465 \mathrm{~nm}\right)$ results in a characteristic line shape emission profile of $\mathrm{Yb}(\mathrm{III})$ at $976 \mathrm{~nm}\left({ }^{2} \mathrm{~F}_{5 / 2} \rightarrow{ }^{2} \mathrm{~F}_{7 / 2}\right)$ in the NIR spectral range (Figure 2) due to a straightforward sensitization mechanism from the $\mathrm{Ru}$-acetylide ligand to the $\mathrm{Yb}$ ion. ${ }^{19}$ This result can be easily explained by the position of the ${ }^{2} \mathrm{~F}_{5 / 2}$ excited state of $\mathrm{Yb}$ (III) $\left(10200 \mathrm{~cm}^{-1}\right)$ relative to the the low lying excited state $\left(465 \mathrm{~nm}, 17000-18000 \mathrm{~cm}^{-1}\right)$ of the complex. As expected, an identical NIR emission spectrum is obtained upon excitation in the TTA 
absorption band $\left(\lambda_{\mathrm{exc}}=330 \mathrm{~nm}\right)$. Concerning the second lanthanide complex 1Eu, the lower energy transition is too low in energy to efficiently sensitize the $\mathrm{Eu}(\mathrm{III})$ luminescence, ie lower than the best accepting ${ }^{5} \mathrm{D}_{1}$ state and almost at the same energy than the ${ }^{5} \mathrm{D}_{0}$ state of the europium(III) center $\left({ }^{5} \mathrm{D}_{1}\right.$ at $19000 \mathrm{~cm}^{-1}$ and ${ }^{5} \mathrm{D}_{0}$ at $\left.17400 \mathrm{~cm}^{-1}\right)$. Thus, the characteristic emission features of the ${ }^{5} \mathrm{D}_{0} \rightarrow{ }^{7} \mathrm{~F}_{\mathrm{J}}(\mathrm{J}=0$-4) transitions characteristic of Eu(III) luminescence at $579(\mathrm{~J}=0), 592(\mathrm{~J}=1), 611(\mathrm{~J}=2), 651(\mathrm{~J}=3)$, and $702 \mathrm{~nm}(\mathrm{~J}=4)$ are obtained upon excitation in the TTA absorption band $\left(\lambda_{\text {exc }}=330 \mathrm{~nm}\right)$ only. However, this complex is not emissive when excited in lower energy transition $\left(\lambda_{\text {exc }}=450 \mathrm{~nm}\right)$, a fact confirmed by the excitation spectrum (detected at $610 \mathrm{~nm}$, Figure S7) that shows an intense band centered at 360 $\mathrm{nm}$ and no detected emission when excitation wavelengths superior to $400 \mathrm{~nm}$ are used. Indeed, the excited state corresponding to the visible MLCT band is probably too low in energy to sensitize efficiently the Eu(III) luminescence. ${ }^{19}$ Overall, these results show that the emission properties of these bimetallic complexes remain after addition of the surface linking chain.
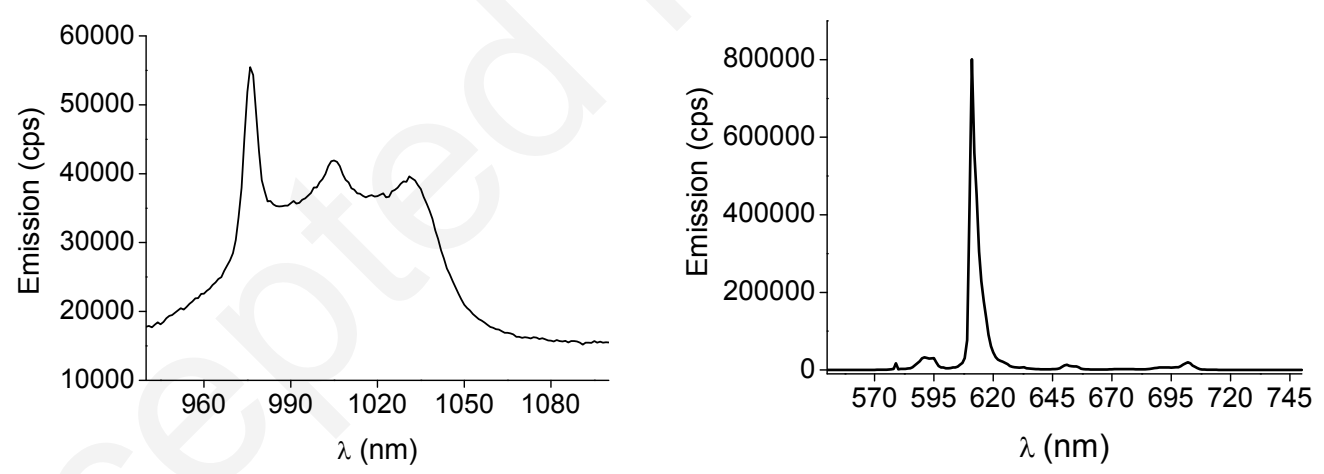

Figure 2. Emission spectra of $\mathbf{1 Y b}\left(\lambda_{\mathrm{ex}}=465 \mathrm{~nm}\right)$ and $\mathbf{1 E u}\left(\lambda_{\mathrm{ex}}=330 \mathrm{~nm}\right)$ at $\mathrm{RT}$ in $\mathrm{CH}_{2} \mathrm{Cl}_{2}$ $\left([\mathrm{C}] \approx 10^{-5} \mathrm{~mol} \cdot \mathrm{L}^{-1}\right)$.

Redox properties in solution. The heterometallic complexes exhibit a reversible oxidation process at ca $0.4 \mathrm{~V}$ vs SCE (see Figure 3, oxidation process of decamethylferrocene at $-0.1 \mathrm{~V}$ vs SCE served as an internal reference). A shift toward more positive potentials ( $0.42 \mathrm{~V}$ vs SCE) is observed for $\mathbf{1 Y b}$ and $\mathbf{1 E u}$ compared to the parent ligand $\mathbf{1}(0.38 \mathrm{~V}$ vs SCE) due to the electro- 
withdrawing lanthanide ions. The oxidation potentials for the two lanthanide organometallics are similar, as expected for a similar solvation shell.

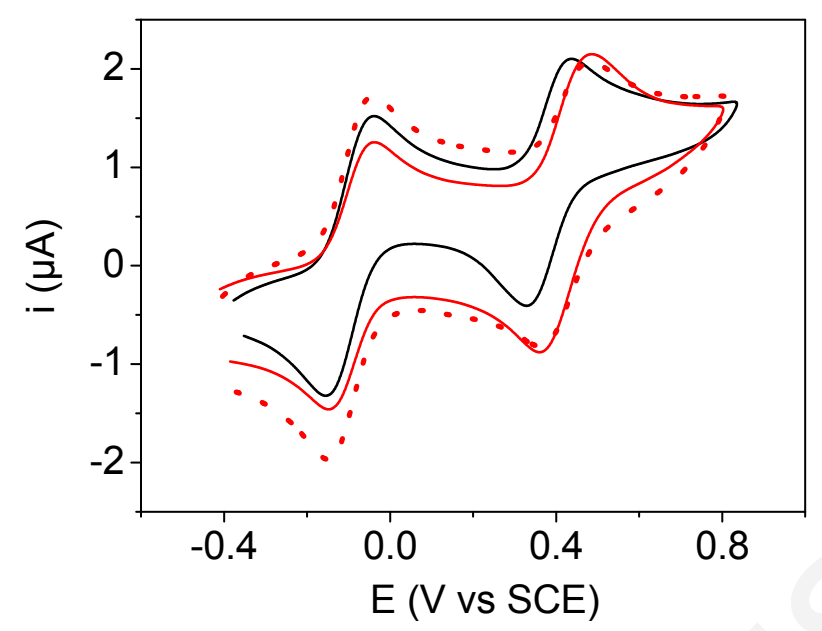

Figure 3. Cyclic voltammetry of $\mathbf{1}$ (black line), $\mathbf{1 E u}$ (red dotted line) or $\mathbf{1 Y b}$ (red line) $\left(\sim 10^{-3}\right.$ $\mathrm{M})$ in $\mathrm{CH}_{2} \mathrm{Cl}_{2}+0.2 \mathrm{M} \mathrm{TBAPF}_{6}$ at a carbon disk electrode in the presence of decamethylferrocene ( $-0.1 \mathrm{~V}$ vs SCE) as internal reference. Scan rate is $0.1 \mathrm{~V} \mathrm{~s}^{-1}$

\section{Self-assembled monolayers: characterization and properties of immobilized} heterobimetallic complexes. Single component SAMs with 1, 1Yb and 1Eu were prepared employing (i) gold plates for spectroscopic, ellipsometry and wettability characterizations, and (ii) gold disk electrodes for electrochemical investigations. The thioacetate group was deprotected in situ by addition of $\mathrm{NH}_{4} \mathrm{OH}$ to the SAMs preparation solution prior to immersion of the gold surface. This procedure was previously used with success with our type of complexes and allows to avoid the formation of multilayer due to undesirable disulphide coupling. ${ }^{25,35}$ After extensive rinsing of the surfaces and drying under a stream of argon, static contact angle measurements were performed using the sessile drop method (Table 1). We observed a change in the surface wettability when the gold surface (contact angle $\theta$ equal to $60 \pm 2^{\circ}$ for a bare clean gold surface) was covered with $\mathbf{1}\left(\theta=67 \pm 2^{\circ}\right)$, with $\mathbf{1 Y b}\left(\theta=76 \pm 2^{\circ}\right)$ and with $\mathbf{1 E u}(\theta=77 \pm$ $\left.4^{\circ}\right)$ 
Infrared reflection absorption spectroscopy (IRRAS) was further employed to characterize the SAMs. Spectra display a band at $2045 \mathrm{~cm}^{-1}$ for SAMs of 1 and $2038 \mathrm{~cm}^{-1}$ for SAMs of $\mathbf{1 Y b}$ and 1Eu, respectively. These bands are characteristic of $\mathrm{Ru}$ acetylide $\mathrm{C} \equiv \mathrm{C}$ stretching vibration band in the monometallic complexes and in the two heterobimetallic complexes (Figure S8), indicating the formation of the SAMs at the gold surfaces.

Estimation of the layers thicknesses was obtained by ellipsometry and reported in Table 1 . The measured thicknesses are consistent with the attachment of a monolayer (or a near monolayer) of 1, 1Eu and 1Yb. However, an increase of thickness was expected for 1Eu and 1Yb compared to $\mathbf{1}$, due to the $\operatorname{Ln}(\mathrm{TTA})_{3}$ contribution. Instead we observed a lower thickness, probably due to a larger tilt angle of the molecules with respect to the normal to the surface in the case of $1 \mathbf{Y b}$ and $\mathbf{1 E u}$ (30 and $47^{\circ}$ as calculated from the measured thicknesses and the estimated molecular lengths).

Table 1. Static contact angle values with water drops and thickness values estimated for SAMs on gold

\begin{tabular}{|c|c|c|c|}
\hline SAM & $\theta$ & Thickness & Estimated \\
& $\left(^{\circ}\right)$ & $(\AA)$ & $\begin{array}{c}\text { molecular length } \\
(\AA)^{\mathrm{a}}\end{array}$ \\
\hline $\mathbf{1}$ & $67 \pm 2$ & $34 \pm 3$ & 29.95 \\
\hline $\mathbf{1 Y b}$ & $76 \pm 2^{\circ}$ & $31 \pm 5$ & 32.98 \\
\hline $\mathbf{1 E u}$ & $77 \pm 4^{\circ}$ & $24 \pm 8$ & 32.98 \\
\hline
\end{tabular}

${ }^{a} \mathrm{Au}-\mathrm{S}$ bonds length is equal to $2.4 \AA$ and the molecular lengths were estimated by using Chem3D software and XRD structures of analogous complexes. ${ }^{19}$

Cyclic voltammetry was recorded in the scan rate range $\left[0.1-200 \mathrm{Vs}^{-1}\right]$ for SAMs incorporating $\mathbf{1}, \mathbf{1 E u}$ and $\mathbf{1 Y b}$ in $\mathrm{CH}_{2} \mathrm{Cl}_{2}$ solution of $\mathrm{NBu}_{4} \mathrm{PF}_{6}$. Figure 4 shows typical 
voltammograms recorded at $20 \mathrm{~V} \mathrm{~s}^{-1}$ (see also Figure S9). A well-defined reversible oxidation system is observed for all SAMs. Apparent formal potential $\mathrm{E}^{\circ}{ }^{\prime}$ is derived from the mid-point between the oxidation and reduction peak potentials. The values are close but positively shifted compared to those obtained in solution, probably because the packing within the SAMs modifies the environment of the electroactive molecules. Interestingly, a $30 \mathrm{mV}$-shift towards more positive potentials is observed for the heterobimetallic Ru-Ln SAMs (1Yb and 1Eu) compared to the Ru-ligand (1), in close connection to the potential shift observed for the complexes in solution (Table 2). This behavior is due to the electron-withdrawing character of the $\operatorname{Ln}(\mathrm{TTA})_{3}$ units which is transmitted through carbon-rich ligands. It is readily retained within immobilized systems in SAMs. Therefore, no decoordination of the lanthanide ions occurs upon surface grafting.

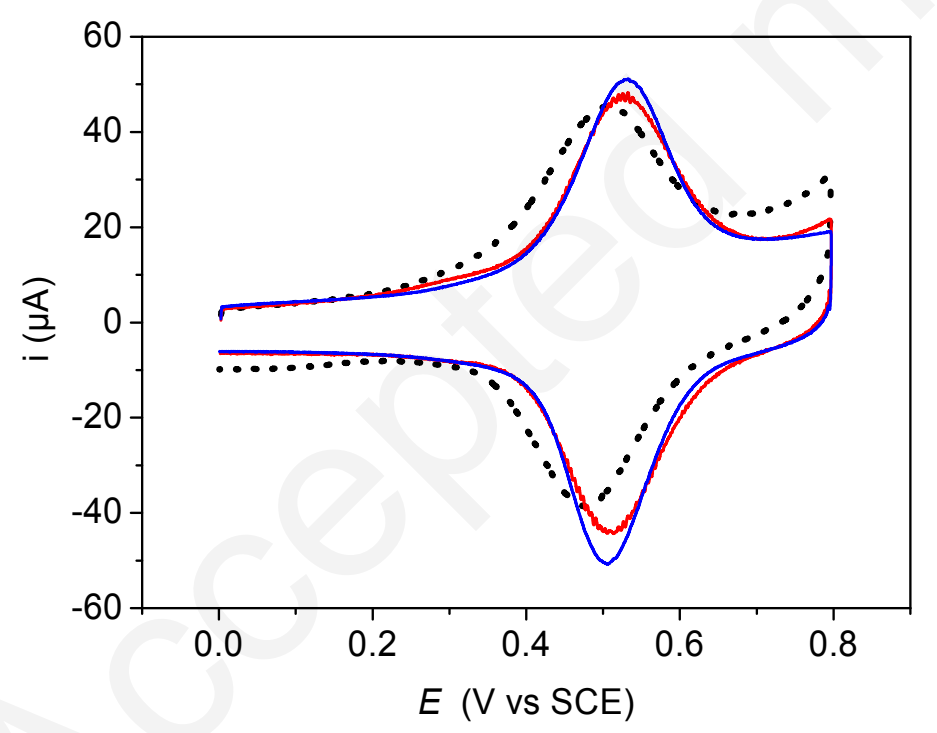

Figure 4. Cyclic voltammograms of $\mathrm{SAMs}$ in $\mathrm{CH}_{2} \mathrm{Cl}_{2}$ containing $0.2 \mathrm{M} \mathrm{NBu}_{4} \mathrm{PF}_{6}$ at gold disk electrode (Ø $1.6 \mathrm{~mm}$ ), for complexes 1 (black dotted line), 1Yb (blue solid line) and 1Eu (red solid line). Scan rate is $20 \mathrm{~V} \mathrm{~s}^{-1}$

As expected for surface-confined species in thin layer, the oxidation peak currents vary as a function of the scan rate (Figure S10). The surface concentrations of the electroactive 
complexes $\Gamma$ were derived from the integration of the electrochemical signals (Table 2). The values vary between 4.7 and $6.0 \times 10^{-11} \mathrm{~mol} \mathrm{~cm}^{-2}$. By taking 1 as a disk of diameter $14.8 \AA$, 1Yb and 1Eu as disk of diameter $17.5 \AA$ (estimated by using the Cambridge scientific Chem3D software) and assuming an hexagonal compact arrangement (closest packing), the maximum theoretical surface concentration is $\Gamma_{\mathrm{CPML}}(\mathbf{1})=8.4 \times 10^{-11} \mathrm{~mol} . \mathrm{cm}^{-2}$ and $\Gamma_{\mathrm{CPML}}(\mathbf{1 L n}) 6.2 \times 10^{-}$ 11 mol. $\mathrm{cm}^{-2}$ for $\mathbf{1}$ and $\mathbf{1 Y b} / \mathbf{1 E u}$, respectively. Thus, our experimental results agree with the formation of a sub-monolayers with a relatively good packing (Table 2). The apparent kinetic rate constants $\mathrm{k}_{\mathrm{ET}}$ with the different SAMs were estimated through numerical simulations of the cyclic voltammograms using KISSA software. ${ }^{32}$ Fast electron transfer kinetics were reached for both monometallic and heterobimetallic systems and $\mathrm{k}_{\mathrm{ET}}$ values were found to be close to $10^{4} \mathrm{~s}^{-1}$, as already reported for closely-related self-assembled complexes. ${ }^{25,35}$

Table 2. Electrochemical data for complexes $\mathbf{1}$ and $\mathbf{1 L n}$ : formal potential in solution, apparent formal potential within SAMs and surface concentration.

\begin{tabular}{|c|c|c|c|}
\hline & $\begin{array}{c}\mathbf{E}^{\circ} \text { (solution) } \\
\text { V vs SCE }\end{array}$ & $\begin{array}{c}\mathbf{E}^{\circ} \text { (SAM) } \\
\text { V vs SCE }\end{array}$ & mol.cm ${ }^{-2}$ \\
\hline $\mathbf{1}$ & 0.38 & 0.49 & $6.0 \times 10^{-11}$ \\
\hline $\mathbf{1 Y b}$ & 0.42 & 0.52 & $5.3 \times 10^{-11}$ \\
\hline $\mathbf{1 E u}$ & 0.42 & 0.52 & $4.7 \times 10^{-11}$ \\
\hline $\mathbf{1}+\mathbf{Y b}$ & - & 0.52 & $3.9 \times 10^{-11}$ \\
\hline $\mathbf{1 + \mathbf { E u }}$ & - & 0.52 & $2.9 \times 10^{-11}$ \\
\hline
\end{tabular}

In a second approach, we investigated the subsequent recruitment of $\operatorname{Ln}(\mathrm{TTA})_{3}$ (with $\operatorname{Ln}=\mathrm{Eu}$ and $\mathrm{Yb}$ ) onto gold surfaces modified with $\mathbf{1}$. The recruitment of the two lanthanides complexes was performed by immersion overnight of gold disk electrodes modified with $\mathbf{1}$ in a $1 \mathrm{mM}$ solution of either $\mathrm{Yb}(\mathrm{TTA})_{3}$ or $\mathrm{Eu}(\mathrm{TTA})_{3}$ in $\mathrm{CH}_{2} \mathrm{Cl}_{2}$. After a thorough rinsing with freshly 
distilled $\mathrm{CH}_{2} \mathrm{Cl}_{2}$, the gold electrodes were analyzed by cyclic voltammetry in $\mathrm{CH}_{2} \mathrm{Cl}_{2}$ containing $\mathrm{NBu}_{4} \mathrm{PF}_{6}$ (Figure 5). Therefore, after immersion in Ln complexes solutions, we still observed a well-resolved electrochemical signal and the redox system is significantly shifted by $30 \mathrm{mV}$ toward more positive potentials, suggesting that $\mathrm{Eu}$ and $\mathrm{Yb}$ complexes were effectively formed at the surface from comparison with Figure 4. This on-surface metalation is also accompanied with a decrease of the signal intensity compared to ligand alone or to selfassembly of the heterobimetallic structures. It is likely that the bulky $\operatorname{Ln}(\mathrm{TTA})_{3}$ complexes require some left space around the terminal bipyridine unit for achieving the complexation, and the "contact" between the immobilized ligand and the Ln complexes modifies the packing and the organization of the SAM, probably resulting in some desorption of ligands or in an incomplete complexation of all the potentially available immobilized ligands. Note however that the surface concentrations remain of the same order of magnitude by comparing direct assembly of $1 \mathbf{L n}$ and assembly of Ln complexes obtained through on-surface metalation. It is worth outlining that the Ln complexation leads to highly stable signals, once the complexation is achieved, since no decrease in signal intensity is observed upon electrochemical cycling. On the whole, the electrochemical analyses show an efficient recruitment of lanthanide complexes at the ligand 1 film. 


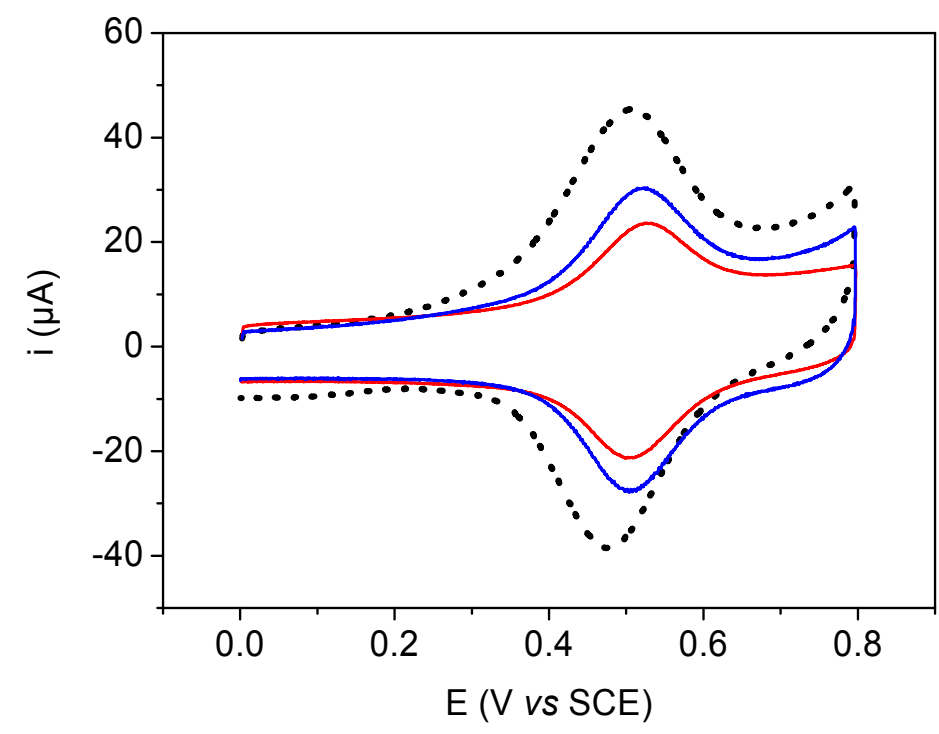

Figure 5. Cyclic voltammetry in $\mathrm{CH}_{2} \mathrm{Cl}_{2}$ containing $0.2 \mathrm{M} \mathrm{NBu}_{4} \mathrm{PF}_{6}$ of a gold disk electrode modified with a SAM of 1 (black dotted line), SAM of 1 after immersion in a solution of $\mathrm{Yb}(\mathrm{TTA})_{3}$ (blue solid line) and SAM of 1 after immersion of $\mathrm{Eu}(\mathrm{TTA})_{3}$ (red solid line).

Self-assembled monolayers of $\mathbf{1}$ and $\mathbf{1 Y b}$ were further successfully prepared onto gold semitransparent substrates (Figure S11) for luminescence emission measurements. In some cases, metallic and especially gold substrates are known to quench luminescence, including that of lanthanides. However, the quenching efficiency is expected to be connected to the spatial distance between the gold substrate and the fluorophore. In a recent work, Davis and coworkers have reported the fluorescence emission of a gold self-assembled monolayer incorporating an europium complex associated with a ferrocene unit, with a bridging unit of 3 nm length as in our present work. ${ }^{14}$ Unfortunately, we were not able to record any emission signal after self-assembly of $\mathbf{1 Y b}$ at gold surface (Figure S12). We believe that the quenching of luminescence that we observed cannot be explained by a too short length of the bridging unit, but rather by the organization of the SAMs (packing and tilt angle with respect to the surface normal). The dangling of $\mathrm{Yb}(\mathrm{TTA})_{3}$ bipyridyl units probably causes a too short distance to the gold surface, leading to a luminescence quenching. 


\section{CONCLUSIONS}

Heterobimetallic systems incorporating an electroactive carbon-rich ruthenium organometallic unit and a lanthanide $(\mathrm{Ln}=\mathrm{Eu}$ and $\mathrm{Yb})$ complex were synthesized and equipped with an anchoring hexylthiol group for subsequent gold surface functionalization. The redox and optical properties were first investigated in solution, showing that (i) the surface linking chain did not modify the properties of the architecture, (ii) dense and well-ordered self-assembled monolayers of heterobimetallic $\mathrm{Ru}-\mathrm{Yb}$ and $\mathrm{Ru}-\mathrm{Eu}$ were formed onto gold surfaces as well as with their monometallic parent ligand. The obtained SAMs were characterized by employing a combination of different techniques, including IRRAS spectroscopy, ellipsometry, contact angle and cyclic voltammetry measurements. The immobilized complexes exhibit fast electron-transfer kinetics $\left(10^{-4} \mathrm{~s}^{-1}\right)$ within SAMs, for both monometallic and bimetallic systems. Interestingly, the complexation of the terminal bipyridyl units with Ln centers is identified through a significant $30 \mathrm{mV}$-potential shift compared to the bare ligand. This redox property is leveraged for demonstrating the efficient ligating recruitment of $\mathrm{Yb}(\mathrm{TTA})_{3}$ and $\mathrm{Eu}(\mathrm{TTA})_{3}$ complexes at the ligand-modified gold electrodes as an efficient alternative method to that of the preformed complex immobilizations and for electrochemical detection of the lanthanide ions. We believe that the work reported herein is a valuable contribution to the preparation and characterization of new lanthanide-containing surface confined architectures. Work is currently in progress to overcome issues related to fluorescence quenching and to take benefit from the association of redox ruthenium acetylide units and of lanthanide complexes.

Supporting Information Available: Synthetic procedures and compound characterization, IR characterization of SAMs, electrochemical data, fluorescence measurements. This material is available free of charge via the Internet at http://pubs.acs.org. 


\section{AUTHOR INFORMATION}

\section{Corresponding Author}

* E-mail: $\quad$ corinne.lagrost@univ-rennes1.fr; $\quad$ stephane.rigaut@univ-rennes1.fr.; lucie.norel@univ-rennes1.fr

\section{Notes}

The authors declare no competing financial interest.

\section{ACKNOWLEDGMENTS}

This work was supported by the Universite de Rennes 1, the CNRS, the Agence Nationale de la Recherche (RuOxLux - ANR-12-BS07-0010-01)). AM thanks the Région Bretagne (SAD Redoxlux) for financial support. Profs. I. Svir, C. Amatore and O. Klymenko are warmly thanked for providing KISSA Software.

\section{SYNOPSIS TOC}

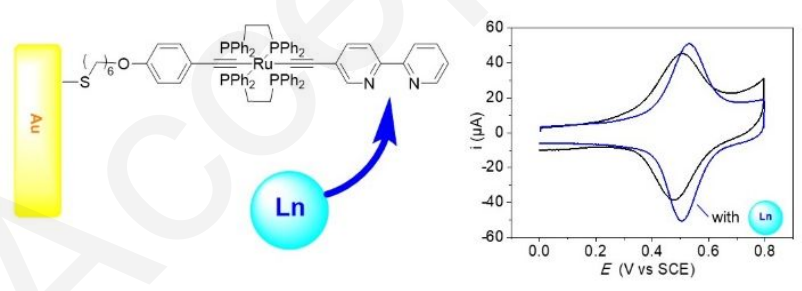




\section{REFERENCES}

1. Love, J. C.; Estroff, L. A.; Kriebel, J. K.; Nuzzo, R. G.; Whitesides, G. M., Self-Assembled Monolayers of Thiolates on Metals as a Form of Nanotechnology. Chem. Rev. 2005, 105, 1103-1170.

2. Vericat, C.; Vela, M. E.; Benitez, G.; Carro, P.; Salvarezza, R. C., Self-Assembled Monolayers of Thiols and Dithiols on Gold: New Challenges for a Well-Known System. Chem. Soc. Rev. 2010, 39, 1805-1834.

3. dos Santos, C. M. G.; Harte, A. J.; Quinn, S. J.; Gunnlaugsson, T., Recent Developments in the Field of Supramolecular Lanthanide Luminescent Sensors and Self-Assemblies. Coord. Chem. Rev. 2008, 252, 2512-2527.

4. Moore, E. G.; Samuel, A. P. S.; Raymond, K. N., From Antenna to Assay: Lessons Learned in Lanthanide Luminescence. Acc. Chem. Res. 2009, 42, 542-552.

5. Bünzli, J.-C. G., Lanthanide Luminescence for Biomedical Analyses and Imaging. Chem. Rev. 2010, 110, 2729-2755.

6. Rodrigues, M., et al., Implementing Thermometry on Silicon Surfaces Functionalized by Lanthanide-Doped Self-Assembled Polymer Monolayers. Adv. Func. Mat. 2016, 26, 200-209.

7. Gulino, A.; Lupo, F.; Condorelli, G. G.; Motta, A.; Fragalà, I. L., Tunable Luminescent Properties of a Europium Complex Monolayer. J. Mat. Chem. 2009, 19, 3507-3511.

8. Del Rosal, I.; Gerber, I. C.; Poteau, R.; Maron, L., Grafting of Lanthanide Complexes on Silica Surfaces Dehydroxylated at $200{ }^{\circ} \mathrm{C}$ : A Theoretical Investigation. New J. Chem. 2015, 39, 7703-7715.

9. Cristaldi, D. A.; Millesi, S.; Mineo, P.; Gulino, A., Europium Complex Covalently Grafted on Si(100) Surfaces, Engineered with Covalent Polystyrene Nanostructures. J. Phys. Chem. C 2013, 117, 16213-16220.

10. Barry, D. E.; Kitchen, J. A.; Albrecht, M.; Faulkner, S.; Gunnlaugsson, T., Near Infrared (Nir) Lanthanide Emissive Langmuir-Blodgett Monolayers Formed Using Nd(III) Directed Self-Assembly Synthesis of Chiral Amphiphilic Ligands. Langmuir 2013, 29, 11506-11515.

11. Hsu, S.-H.; Yilmaz, M. D.; Blum, C.; Subramaniam, V.; Reinhoudt, D. N.; Velders, A. H.; Huskens, J., Expression of Sensitized Eu3+ Luminescence at a Multivalent Interface. J. Am. Chem. Soc. 2009, 131, 12567-12569.

12. Murray, N. S.; Jarvis, S. P.; Gunnlaugsson, T., Luminescent Self-Assembly Formation on a Gold Surface Observed by Reversible 'Off-on' Switching of Eu(III) Emission. Chem. Commun. 2009, 4959-4961.

13. Lehr, J.; Bennett, J.; Tropiano, M.; Sørensen, T. J.; Faulkner, S.; Beer, P. D.; Davis, J. J., Reversible Recruitment and Emission of DO3a-Derived Lanthanide Complexes at Ligating Molecular Films on Gold. Langmuir 2013, 29, 1475-1482.

14. Lehr, J.; Tropiano, M.; Beer, P. D.; Faulkner, S.; Davis, J. J., Reversible Redox Modulation of a Lanthanide Emissive Molecular Film. Chem. Commun. 2015, 51, 6515-6517.

15. Mefteh, W. B.; Touzi, H.; Bessueille, F.; Chevalier, Y.; Kalfat, R.; Jaffrezic-Renault, N., An Impedimetric Sensor Based on a Gold Electrode Functionalized with a Thiol Self-Assembled Monolayer Modified by Terpyridine Ligands for the Detection of Free Gadolinium Ions. Electroanalysis 2015, 27, 84-92.

16. Comby, S.; Gunnlaugsson, T., Luminescent Lanthanide-Functionalized Gold Nanoparticles: Exploiting the Interaction with Bovine Serum Albumin for Potential Sensing Applications. ACS Nano 2011, 5, 7184-7197.

17. Lewis, D. J.; Day, T. M.; MacPherson, J. V.; Pikramenou, Z., Luminescent Nanobeads: Attachment of Surface Reactive Eu(Iii) Complexes to Gold Nanoparticles. Chem. Commun. 2006, $1433-1435$.

18. Truman, L. K.; Comby, S.; Gunnlaugsson, T., Ph-Responsive Luminescent LanthanideFunctionalized Gold Nanoparticles with "on-Off" Ytterbium Switchable near-Infrared Emission. Angew. Chem. Int. Ed. 2012, 51, 9624-9627.

19. Norel, L.; Di Piazza, E.; Feng, M.; Vacher, A.; He, X.; Roisnel, T.; Maury, O.; Rigaut, S., Lanthanide Sensitization with Ruthenium Carbon-Rich Complexes and Redox Commutation of nearIR Luminescence. Organomet. 2014, 33, 4824-4835. 
20. Di Piazza, E.; Norel, L.; Costuas, K.; Bourdolle, A.; Maury, O.; Rigaut, S., d-f Heterobimetallic Association between Ytterbium and Ruthenium Carbon-Rich Complexes: Redox Commutation of nearIR Luminescence. J. Am. Chem. Soc. 2011, 133, 6174-6176.

21. Luo, L.; Benameur, A.; Brignou, P.; Choi, S. H.; Rigaut, S.; Frisbie, C. D., Length and Temperature Dependent Conduction of Ruthenium-Containing Redox-Active Molecular Wires. $J$. Phys. Chem. C 2011, 115, 19955-19961.

22. Norel, L.; Feng, M.; Bernot, K.; Roisnel, T.; Guizouarn, T.; Costuas, K.; Rigaut, S., Redox Modulation of Magnetic Slow Relaxation in a 4f-Based Single-Molecule Magnet with a 4d CarbonRich Ligand. Inorg. Chem. 2014, 53, 2361-2363.

23. Liu, Y.; Ndiaye, C. M.; Lagrost, C.; Costuas, K.; Choua, S.; Turek, P.; Norel, L.; Rigaut, S., Diarylethene-Containing Carbon-Rich Ruthenium Organometallics: Tuning of Electrochromism. Inorg. Chem. 2014, 53, 8172-8188.

24. Murai, M.; Sugimoto, M.; Akita, M., Zinc-Porphyrins Functionalized with Redox-Active Metal Peripherals: Enhancement of $\mathrm{D} \pi-\mathrm{P} \pi$ Interaction Leading to Unique Assembly and Redox-Triggered Remote Switching of Fluorescence. Dalton Trans. 2013, 42, 16108-16120.

25. Mulas, A.; Hervault, Y.-M.; He, X.; Di Piazza, E.; Norel, L.; Rigaut, S.; Lagrost, C., Fast Electron Transfer Exchange at Self-Assembled Monolayers of Organometallic Ruthenium(II) $\sigma$ Arylacetylide Complexes. Langmuir 2015, 31, 7138-7147.

26. He, X.; Lagrost, C.; Norel, L.; Rigaut, S., Ruthenium(II) $\sigma$-Arylacetylide Complexes as Redox Active Units for (Multi-)Functional Molecular Devices. Polyhedron 2018, 140, 169-180.

27. Grelaud, G.; Gauthier, N.; Luo, Y.; Paul, F.; Fabre, B.; Barrière, F.; Ababou-Girard, S.; Roisnel, T.; Humphrey, M. G., Redox-Active Molecular Wires Derived from Dinuclear Ferrocenyl/Ruthenium(II) Alkynyl Complexes: Covalent Attachment to Hydrogen-Terminated Silicon Surfaces. J. Phys. Chem. C 2014, 118, 3680-3695.

28. Hoogvliet, J. C.; Dijksma, M.; Kamp, B.; van Bennekom, W. P., Electrochemical Pretreatment of Polycrystalline Gold Electrodes to Produce a Reproducible Surface Roughness for Self-Assembly: A Study in Phosphate Buffer pH 7.4. Anal. Chem. 2000, 72, 2016-2021.

29. Rand, D. A. J.; Woods, R., The Nature of Adsorbed Oxygen on Rhodium, Palladium and Gold Electrodes. J. Electroanal. Chem. 1971, 31, 29-38.

30. Valette, G., Hydrophilicity of Metal Surfaces: Silver, Gold and Copper Electrodes. J. Electroanal. Chem. 1982, 139, 285-301.

31. Yang, H. C.; Aoki, K.; Hong, H. G.; Sackett, D. D.; Arendt, M. F.; Yau, S. L.; Bell, C. M.; Mallouk, T. E., Growth and Characterization of Metal(II) Alkanebisphosphonate Multilayer Thin Films on Gold Surfaces. J. Am. Chem. Soc. 1993, 115, 11855-11862.

32. Amatore, C.; Klymenko, O.; Svir, I., A New Strategy for Simulation of Electrochemical Mechanisms Involving Acute Reaction Fronts in Solution: Application to Model Mechanisms. Electrochem. Commun. 2010, 12, 1165-1169.

33. Grosshenny, V.; Romero, F. M.; Ziessel, R., Construction of Preorganized Polytopic Ligands Via Palladium-Promoted Cross-Coupling Reactions. J. Org. Chem. 1997, 62, 1491-1500.

34. Benameur, A.; Brignou, P.; Di Piazza, E.; Hervault, Y.-M.; Norel, L.; Rigaut, S., Redox-Active Ruthenium(II) $\sigma$-Arylacetylide Wires for Molecular Electronics Incorporating Insulating Chains. New J. Chem. 2011, 35, 2105-2113.

35. Mulas, A.; Hervault, Y.-M.; Norel, L.; Rigaut, S.; Lagrost, C., Electron-Transfer Kinetics in Polymetallic Carbon-Rich Ruthenium(II) Bis( $\sigma$-Arylacetylides) Wires Connected to Gold. ChemElectroChem 2015, 2, 1799-1805. 